Clemson University

TigerPrints

2-2019

(Mis)Alignments in Mentorship: Exploring Challenges to Preservice Science Teacher Preparation

Mandy Biggers

Alison Riley Miller

Laura Zangori

Brooke A. Whitworth

Follow this and additional works at: https://tigerprints.clemson.edu/teach_learn_pub

Part of the Science and Mathematics Education Commons 


\section{Journal of Science Teacher Education}

\section{(Mis)Alignments in Mentorship: Exploring Challenges to Preservice Science Teacher Preparation}

\section{Mandy Biggers, Alison Riley Miller, Laura Zangori \& Brooke A. Whitworth}

To cite this article: Mandy Biggers, Alison Riley Miller, Laura Zangori \& Brooke A. Whitworth (2019): (Mis)Alignments in Mentorship: Exploring Challenges to Preservice Science Teacher Preparation, Journal of Science Teacher Education, DOI: 10.1080/1046560X.2018.1562812

To link to this article: https://doi.org/10.1080/1046560X.2018.1562812

Published online: 27 Feb 2019.

Submit your article to this journal $\sqsubset$

山 Article views: 6

View Crossmark data $\complement$ 


\title{
(Mis)Alignments in Mentorship: Exploring Challenges to Preservice Science Teacher Preparation
}

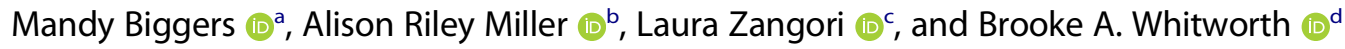

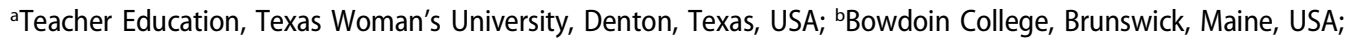

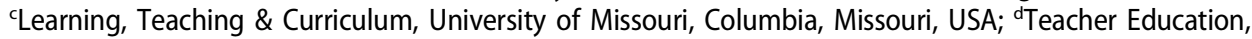 \\ University of Mississippi, University, Mississippi, USA
}

\begin{abstract}
The mentoring relationships between preservice teachers and their cooperating teachers have been established as critical to the retention or attrition of novice teachers (Clarke, Triggs, \& Nielsen, 2014), yet little research has been conducted to examine what factors around mentor teacher selection and support are most salient to creating strong mentoring structures. In this study, we investigated how four U.S. states (one in the Southwest, one in the Northeast, one in the Midwest, and one in the South) recruit mentor teachers for secondary science preservice teachers, what requirements the mentor teachers must possess, how mentor teachers are incentivized to serve in this role, and whether the use of science standards influences decisions related to preservice teacher placement. Our results show that (a) mentor placements are often found through word-of-mouth versus more formalized systems, (b) there is a wide variety of incentives offered to mentor teachers, (c) there is a common minimum standard for teachers to qualify as mentor teachers, and (d) that science standards, including individual state standards or the Next Generation Science Standards, are central to preservice teacher education programs but are not frequently considered by these same programs when they place a preservice teacher with a mentor teacher. Our findings indicate the need for further research to identify what factors are most salient in strong mentoring relationships and what steps can be taken to support and strengthen the mentoring between preservice teachers and their mentor teachers.
\end{abstract}

\section{KEYWORDS}

mentor teachers; preservice teachers; science teacher education

The mentoring relationships teachers develop with other teachers are a critical form of professional development, both for teacher professional growth and for teacher retention (Clarke, Triggs, \& Nielsen, 2014; Smith \& Ingersoll, 2004). The first opportunity teachers have to form mentoring relationships with in-service teachers occurs during their student teaching practicums when student teachers are placed in a classroom with a mentor teacher for a period of time (Clarke et al., 2014). Beginning teachers consider this experience a vital contribution to their teacher preparation (Blocker \& Swetnam, 1995; Grossman, Ronfeldt, \& Cohen, 2012). For science teachers in particular, this initial mentoring relationship is a linchpin for their beginning practice, serving as a basis for their future mentoring relationships and a link to their retention in the profession (Ingersoll \& Perda, 2010; Rozelle \& Wilson, 2012). 
With the release of the Next Generation Science Standards (NGSS; NGSS Lead States, 2013), this initial mentoring relationship takes on increased significance in terms of supporting beginning teachers in understanding and incorporating the NGSS in their practice. Note that none of the four states in this study have officially adopted the NGSS, yet all four of the states are in the process of adopting them or have revised state standards to align with the NGSS. In addition, individual school districts or individual teachers within these states may have chosen to incorporate the NGSS into their science teaching regardless of state adoption or school and district support. Finally, science teacher education programs are encouraged to align teacher preparation with the NGSS independent of state adoption so that those preservice teachers (PSTs) are prepared for employment within and beyond their particular state (National Science Teachers Association, 2017).

Although our states have not adopted the NGSS, we as faculty in science teacher education programs are preparing students for more than in-state jobs. We familiarize our students with the NGSS because they are the most current reform in science education. Our education preparation programs are aligned with the NGSS, yet there is a disconnect when students are placed in classrooms in which teachers are unfamiliar with the NGSS. Our purpose for including this feature in the current study was to capture this disconnect and question how education preparation programs might address it. This, along with known variations in mentor teachers' practice and ability to mentor (FeimanNemser \& Buchman, 1985; Grossman et al., 2012), sets the stage to create even wider misalignment between what PSTs encounter during their student practicum experiences and the goals of science teacher education programs.

The selection of mentor teachers is a part of teacher education that has historically received little direction from state teacher certification agencies (Greenberg, Pomerance, \& Walsh, 2011). Yet for PSTs to have experiences in their practicums that align with their teacher education programs, the selection of mentor teachers should align with science teacher preparation program goals (Grossman et al., 2012). To explore what criteria are currently considered for mentor teacher selection, we sent a questionnaire to all colleges and universities that have secondary science teacher certification programs across four states in different geographical locations (Northeast, Midwest, South, and Southwest) to explore how they select their mentor science teachers. Questions guiding this study were as follows:

(1) What requirements do preservice science teacher education programs have for mentor science teachers?

(2) In what ways do these requirements align from program to program and from state to state?

(3) In what ways does the alignment of PST preparation programs with the NGSS impact those programs' ability to recruit qualified mentor teachers in states that have not yet adopted the NGSS?

\section{Mentor teachers' roles in PST education}

Mentor teachers should have the ability to share their experience and knowledge and to serve as supervisors, collaborators, coaches, and advocates (Comstock, 2013; Shamoo \& Resnik, 
2009). Ideally, mentors should be invested in and sincerely care about the future growth and development of a mentee (Virginia Commonwealth University, 2002). However, the selection of mentor teachers across disciplines has historically been haphazard, with the focus on finding teachers who were willing to host a student practicum in their classroom rather than whether the mentor teachers' beliefs and knowledge aligned with those of the teacher education programs (Clarke et al., 2014).

In addition, the role of the mentor teacher has remained ill defined at federal and state levels, leaving colleges and universities with little direction for how to support mentor teachers (Clarke et al., 2014; Greenberg et al., 2011). The lack of information on mentor teachers' role causes them to rely on their own prior student practicum experiences to determine how involved or removed they should be and what knowledge and beliefs they should support the PST in developing and refining during the student teaching practicum (Clarke et al., 2014; Grossman et al., 2012). Given the limited guidance provided to mentor teachers, it becomes clear how large disconnects occur between theories taught in teacher education and what student teachers observe and experience within their mentor teachers' classrooms and schools (Feiman-Nemser \& Buchman, 1985; Greenberg et al., 2011; Grossman et al., 2012).

These historical disconnects across mentor teachers and student practices remain a prevalent issue within science education (Bhattacharyya, Volk, \& Lumpe, 2009; Haney \& McArthur, 2002; Rozelle \& Wilson, 2012; Zembal-Saul, Krajick, \& Blumenfeld, 2002) and become particularly crucial when contextualized within the national shortage of qualified secondary science teachers. Title II data reported across the four states in this study for the 2015-2016 academic year illustrate that numbers of secondary science certificates are low relative to numbers of other secondary certificates (e.g., social studies or English language arts). Across the four states, only 426 certificates in secondary science were awarded relative to 568 and 662 certificates in social studies and English language arts, respectively (see Table 1). Furthermore, those numbers pale in comparison to the 3,545 general elementary certificates awarded that same year. In a landscape where qualified science teachers are hard to come by, it is paramount that both their preparation and mentorship in the field be well aligned and supported such that these novice science teachers have the opportunity to persist and to thrive in the profession.

We anticipate that as more states adopt the NGSS, this disconnect will become more widespread if NGSS alignment is not considered in science mentor teacher selection. Few NGSS-aligned curriculum materials are available, which places the burden on districts, schools, and teachers to align their lessons to enact three-dimensional science learning and provide

Table 1. Teaching certificates awarded for the 2015-2016 academic year by discipline.

\begin{tabular}{lccccccc}
\hline State & $\begin{array}{c}\text { Life } \\
\text { science }\end{array}$ & $\begin{array}{c}\text { Physical } \\
\text { science }\end{array}$ & $\begin{array}{c}\text { General } \\
\text { science }\end{array}$ & Math & $\begin{array}{c}\text { Social } \\
\text { studies }\end{array}$ & $\begin{array}{c}\text { English language } \\
\text { arts }\end{array}$ & $\begin{array}{c}\text { General } \\
\text { elementary }\end{array}$ \\
\hline Southwest & 109 & 55 & 28 & 163 & 218 & 273 & 1,309 \\
Northeast & 16 & 10 & & 16 & 42 & 31 & 181 \\
South & 68 & 9 & & 35 & 96 & 120 & 542 \\
Midwest & 82 & 26 & 23 & 128 & 212 & 238 & 1,513 \\
Total & 275 & 100 & 51 & 342 & 568 & 662 & 3,545 \\
\hline
\end{tabular}

Note. Data are from the 2015-2016 Title II report, the most recent report available. 
NGSS professional development opportunities (National Academies of Sciences, Engineering, and Medicine, 2018). With few available curriculum materials and professional development dependent on the school district, mentor teachers may not be comfortable with and/or feel prepared to teach NGSS-aligned lessons (National Academies of Sciences, Engineering, and Medicine, 2018). Therefore, a disconnect between three-dimensional science learning might occur, much like the disconnect between science inquiry (National Research Council, 1996) and classroom lesson enactments occurred with the prior science standards.

\section{Methods}

This study was part of a larger research project investigating the mentoring relationship between mentor teachers and their PSTs. The data for this study were analyzed using qualitative methods. Data sources included questionnaires sent to teacher education programs across four states. The data provide a broad perspective on the approaches of PST education programs to recruiting and pairing mentor teachers with PSTs.

\section{Participants}

The questionnaire was sent to a convenience sample based on the states where we work. It was sent to all teacher education programs that offer secondary science certification within each of the four states, for a total of 51 programs. The questionnaire was collected using Qualtrics software. It was completed by 28 college and university program directors and/ or coordinators (a 55\% response rate, see Table 2) across four states (northeastern, Midwestern, southern, and southwestern United States). These individuals were not necessarily specific to science education but were the responsible agents for the field placement of all education students, including science education students, in the program.

\section{Sources of data}

A PST education program questionnaire was developed based on the literature (see the Appendix). The development and design of the questionnaire was informed by and aligned with best practices (Dillman, Smyth, \& Christian, 2014). In designing the questionnaire, two researchers wrote and developed an initial set of questions. Prior to administration, the questionnaire was reviewed by a panel of three experts in science education and PST education in order to establish support for face and content validity (Haynes, Richard, \& Kubany, 1995; Newman \& McNeil, 1998). Through two rounds of review, the panel recommended changes that were incorporated into the final version of the questionnaire.

Table 2. Questionnaire response rates by state.

\begin{tabular}{lccc}
\hline State & No. of questionnaires sent & No. of responses received & Response rate \\
\hline Southwest & 9 & 3 & $33.3 \%$ \\
Northeast & 14 & 11 & $78.6 \%$ \\
South & 11 & 6 & $54.5 \%$ \\
Midwest & 17 & 8 & $55 \%$ \\
Total & 51 & 28 & $55.35 \%^{\mathrm{a}}$ \\
\hline
\end{tabular}

${ }^{\text {a Average. }}$ 
The final version of the questionnaire collected the respondent's name, the program name, the number of science PSTs who would be completing their student teaching during the upcoming academic year, and the number of student teachers in science who had been placed each year for the previous three academic years. It also included the following questions:

(a) How do you recruit mentor teachers for science teaching practicum placements?

(b) What qualifications must a science teacher have in order to be selected as a mentor teacher for your program?

(c) Does adherence of individual mentor teachers or whole schools to science standards, whether state or national (NGSS) play a role in where you place student teachers?

(d) What are the expectations and responsibilities of mentor teachers who work with your program?

(e) What incentives, if any, is a mentor teacher offered for mentoring a student teacher?

(f) Are there other things that are important to note?

A link to the questionnaire was sent to the teacher education program coordinator for each institution along with a brief description of the study.

\section{Analysis of data}

The entire questionnaire included 12 questions, but for this study we focused on responses to a subset of five of these questions. Each respondent answered all 12 questions, so there were no missing data points. The subset of five questions focused on the recruitment and qualifications of mentor teachers, incentives for mentor teachers, and the role of standards in placing PSTs with mentor teachers.

Questionnaire data were exported into a matrix-style spreadsheet and analyzed using classical content analysis (Patton, 2002) for each individual questionnaire question.

In the first round of coding, responses were analyzed without regard to which state they were from. Answers from all participants were organized into a matrix categorized by question answer. All answers were grouped by question. The responses ranged from single-word answers (i.e., "yes," "no") to multiple paragraphs.

We looked for patterns across the respondents. Data reduction and verification of patterns resulted in themes for each question. The themes found in each question are reported in the Results. In a second round of analysis, we divided the responses to each question by state to look for patterns within states. No patterns within states were found, and therefore none are reported here.

\section{Results}

Results are organized by question in order to give an overview of the results for each topic. The topics presented within the subset of questions chosen for this article are as follows: (a) how mentor teachers are recruited, (b) what qualifications mentor teachers are 
required to have in order to be considered for the position, (c) how mentor teachers are retained and incentivized, and (d) expectations and responsibilities of mentor teachers.

\section{Recruitment of science mentor teachers}

We asked the programs "How do you recruit mentor teachers for science teaching practicum placements?" and the answers $(n=28)$ clustered around three main themes. First, word of mouth was the most common way to recruit mentor teachers. Mentor teachers often knew someone within the teacher education program. Representative answers that exemplify this idea are as follows: "I have a network of people I ask" (Peter), "Word of mouth, talking with strong teacher mentors to get their recommendations, vetting through meetings/conversations" (Sally), and "Reach out to department chairs to ask for recommendations" (Ashley). As these examples show, recruiting mentor teachers was most often achieved through informal structures rather than via more formal processes.

Second, programs relied heavily on administrator and/or field supervisor recommendations for their recruiting. The idea of building relationships over time seemed an important tool in recruiting mentor teachers. For example, Lisa stated, "We consult principals and teachers that we work with," and Bonnie said, "Field supervisors work through the school principal." Relationships have been developed with the schools over the years and placements are determined by principal/supervisor. Todd stated that the "suggestion of a principal; or school volunteer coordinator" would be his method of recruiting mentor teachers. In these instances, the mentor teacher was recommended by someone who knew someone in the program; this could therefore be considered an extension of word-ofmouth recruitment.

The third theme was using program alumni as mentor teachers. Karla mentioned that she liked to "ask alumns [sic] in the area after several years of experience," and Ben stated that he was "increasingly able to use our own program graduates" in recruitment. Using their own program graduates can be beneficial to teacher education programs, because they know how that particular mentor teacher was trained. In addition, using graduates of the program served as a recruiting tool for future mentor classrooms because PSTs had a commonality with their mentor teacher (both attended the same teacher education program). This provided a means for PSTs to view themselves as eventual alumni mentoring a future PST from the same program. In addition, placing student teachers in program graduates' classrooms showed confidence and trust in the teachers they had become and in the goals of their program.

In addition to these three themes, other less common considerations were mentioned as reasons for recruiting mentor teachers, such as classrooms being within a particular distance of campus (i.e., "placements within 30 miles") and a few programs allowing the school district to make their own placements. The three considerations discussed here(a) word of mouth, (b) the recommendation of a principal or supervisor, and (c) former program graduates-were the most common responses to the question about how mentor teachers were recruited for student teacher placements in the teacher education programs.

\section{Qualification requirements of mentor teachers}

Once names of possible mentor teachers were suggested, programs determined whether the teachers were qualified to serve in the role of mentor to a PST. The question 
Table 3. State minimum requirements to serve as a mentor teacher.

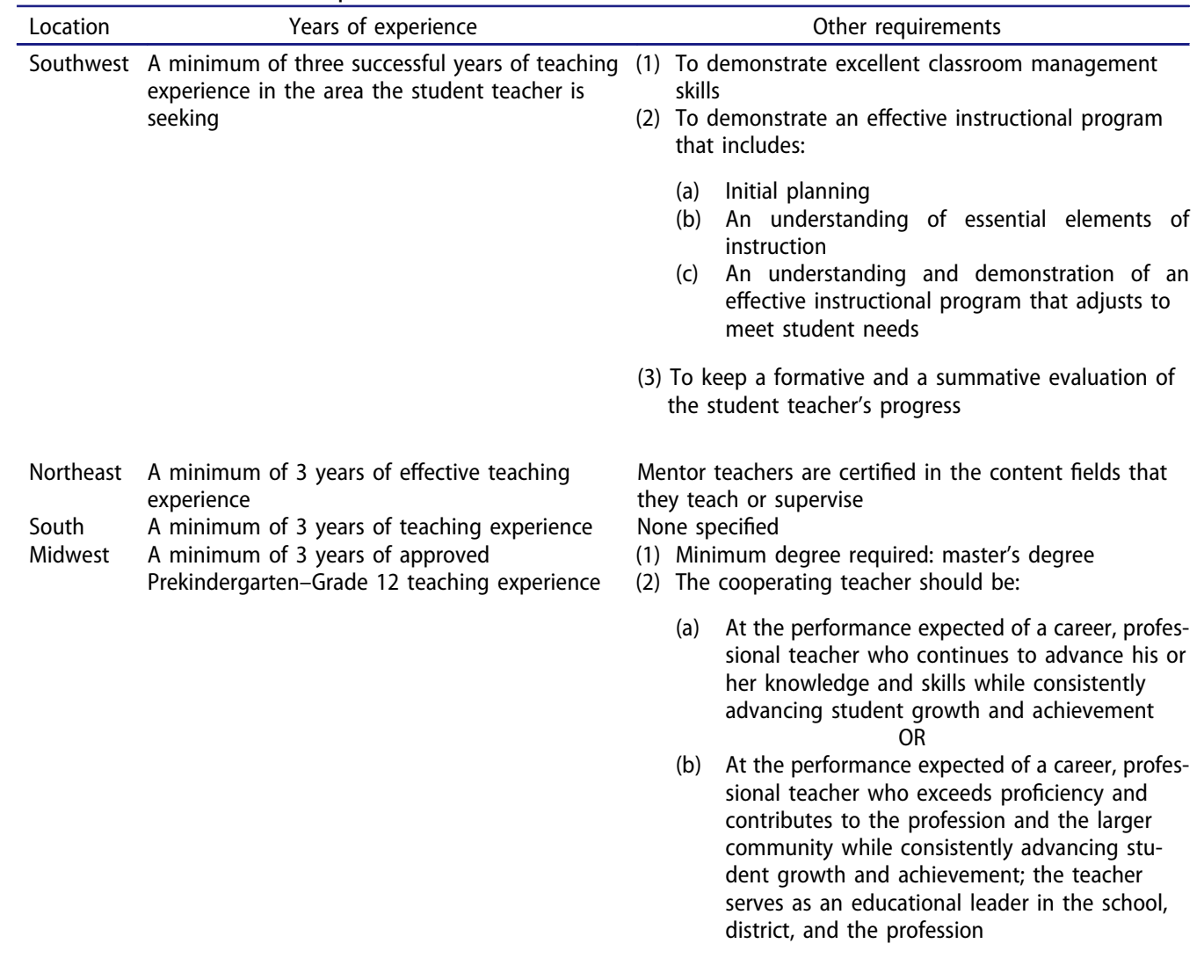

examining the qualification requirements of mentor teachers showed the greatest alignment across programs. The responses included two main themes: (a) minimum years of teaching experience and (b) the recommendation of an administrator.

The minimum requirement for all programs was 3 years of teaching experience. This aligned with the minimum teaching experience requirements set by the states' departments of education, represented in Table 3 (data collected from participating states Department of Education websites). Two programs required 4 years of experience and one program had a 5-year requirement, however. A few programs $(n=4)$ went on to specify that these years of experience had to be within the discipline the teacher was currently teaching and would be mentoring. For example, 3 years of experience teaching life science would not qualify a teacher to mentor a student teacher in earth science.

The other common theme was recommendations from an administrator or department. A representative response from this category came from Ben. He stated, "I require references from other teachers or administrators I know and trust to give me a candid assessment." Similarly, Karla stated, "If we need to find new placement for someone who does not work with us, recommendations from school administration is needed."

Two programs required a graduate degree $(n=2)$, although it was not clear whether that graduate degree needed to be in content (biology, chemistry, physics, earth science) or 
pedagogy (curriculum/teaching, science education). One program stated that it recruits "highly qualified teachers who demonstrate academic competence and effective teaching (measured by student achievement)." Another mentioned that the teacher had to have "excellent classroom management skills." Finally, one program responded that the teacher only needed a state teaching license to be qualified as a mentor teacher.

\section{Incentives and benefits for mentor teachers}

In addition to responses about how mentor teachers were recruited and who was qualified to serve in this role, we also examined the answers to the question "What incentives, if any, is a mentor teacher offered for mentoring a student teacher?" The analysis found one theme: Mentor teachers were provided incentives; however, the incentives varied widely by program. Cash incentives ranging from $\$ 75$ to $\$ 500$ were common $(n=5$ programs specified that a stipend was provided but did not provide the amount of the stipend). Four programs offered continuing education units toward a teacher's certification requirements, whereas others $(n=3)$ provided access to the associated university's facilities, such as the library, gym, or pool. One program responded that it offered the mentor teachers light food and/or snacks at its campus, whereas another program stated that it "give[s] them a gift and tickets to sporting events or plays on campus. We do not have a monetary stipend" (Moira). One curt response stated that the incentive for the mentor teacher is "the help of the intern" (Jeremy).

\section{Expectations and responsibilities}

When we asked the programs "What are the expectations and responsibilities of mentor teachers who work with your program?" we got the most text-rich responses of all 12 questions on the questionnaire. The responses fell into three themes: (a) formal evaluation, (b) informal evaluation, and (c) cooperating with the teacher education program.

\section{Formal evaluation of the student teacher}

Almost all $(n=21)$ of the programs responded that they expected the mentor teachers to formally evaluate the student teachers at least once during the placement semester. Many of the programs $(n=10)$ specifically mentioned that they included two formal evaluations (midterm and final). In some cases, these were aligned with standards such as the Interstate Teacher Assessment and Support Consortium or the Department of Elementary and Secondary Education. Lisa summed it up in the following way:

\footnotetext{
The mentor teacher's main responsibility is to help the student teacher in understanding and learning how to assume the role of a professional classroom teacher. This responsibility requires positive, supportive supervision of the student teacher that includes modeling, guidance, and feedback on the student teacher's progress. Sticky notes are included in the packet for the mentor teacher to use to jot down both positive notes and constructive criticism while the student teacher is teaching. A successful student teaching experience is directly related to the actions of the mentor teacher.
}

This statement captured the vital role of mentor teachers in the guidance of PSTs. 


\section{Informal evaluation of the student teacher}

The mentor teachers were expected to provide informal feedback to the PSTs in the form of observations, critiques, coplanning sessions, mentoring, and advising. Some programs $(n=2)$ utilized (and/or required) video recording of the student teachers' lessons as part of their informal feedback. According to Lucy,

Mentor teachers are expected to provide regular feedback to the student teacher, including observations, critiques, advice, etc. Videotaping of the student teacher is required, and it helps the student teacher take on this responsibility when there is encouragement and assistance from the mentor teacher.

This feedback occurred as the PSTs took over more and more responsibility for teaching in their classroom.

\section{Working with the university teacher education program}

The mentor teacher worked in concert with the university during the placement. This was achieved by working with the university supervisor, attending orientation meetings, and following procedures and requirements of each program. Dorothy stated, "Teachers are expected to follow our guidelines, which are shared at the start of each academic year." Four respondents provided a link to their program handbook for mentor teachers or copied and pasted their responses directly from their program handbook. Blanche stated that mentor teachers are "provided with orientation packet and receive information in a face to face orientation meetings." It was clear across the responses that most programs had some sort of oversight and procedural process for their mentor teachers.

\section{Science standards}

When we asked the programs whether the adherence of individual mentor teachers or whole schools to science standards (whether state or national) played a role in where student teachers were placed, the results were dualistic. The responses $(n=28)$ were almost evenly split between "yes" and "no" answers. Eleven of the respondents noted that they took science standards into consideration when making student teaching placements. In contrast to the lengthy answers about expectations and responsibilities, their answers ranged from single "yes" answers to more lengthy justifications. One program said, "They must adhere to the [state] standards." Another stated,

Yes. We want our students placed in a classroom where standards are in place ... at least the [state] standards. We do have a preference for mentors who are familiar with the NGSS, and ask our students to use both [state] and NGSS standards.

One replied with an emphatic "Absolutely!"

In contrast, 12 respondents replied that this did not play a role in deciding where to place student teachers. Most answers in this category were a simple one word "no." It is interesting that one respondent answered, "No, although it probably should, huh?" 


\section{Discussion and recommendations}

Despite targeted recruitment of teachers in science, technology, engineering, and mathematics fields, there remains a shortage of highly qualified science teachers (Cross, 2017; Ingersoll \& Perda, 2010). One reason for the shortage is that science teachers leave the profession before retirement for a number of different reasons that all coalesce around overall job dissatisfaction (Ingersoll \& Perda, 2010). When both preretirement and retiring teachers leave the profession simultaneously, and fewer science teachers enter the profession, there is an imbalance, so districts are left with more open science teacher positions than there are science teachers available to hire.

One critical support for the retention of beginning science teachers is the development of a strong mentor-mentee relationship with another teacher (Smith \& Ingersoll, 2004). Beginning teachers first experience these relationships during their student teaching practicum, in which the beliefs and practices expressed by their mentor teacher serve as a baseline for them to build their own teaching practice (Bhattacharyya et al., 2009; Rozelle \& Wilson, 2012; van Driel, Verloop, \& de Vos, 1998; Zembal-Saul et al., 2002). Yet our results suggest that the only requirement used to recruit mentor teachers is the recommendation of other teachers or principals with whom the field office has preexisting relationships. The program typically does not consider the mentor teacher's ability to provide necessary supports to a PST. This finding demonstrates that not much has changed with mentor teacher selection since Blocker and Swetnam surveyed colleges and universities in 1995. Blocker and Swetnam (1995) found that regardless of the size of the institution, colleges and universities had few requirements for selecting mentor teachers and offered little to no support for mentor teachers in hosting a student teacher, as we also found in our responses.

Although responding teacher preparation programs appeared to align with state standards, these requirements are minimal, with most states setting baseline requirements for mentor teachers rather than discerning whether a mentor teacher is qualified to host a student teacher or prepared to fully support the development of PSTs. Our recommendations in response to this finding are that, at a minimum, mentor science teachers should be selected based on their alignment with the goals of the teacher education program, or programs should provide professional development for mentor teachers. Training could be provided through online platforms that also give continuing education credits for participating in mentor training. This effort would provide more coherency for PSTs than what they currently experience in their student practicums.

Furthermore, the broad change within science education that implementing the NGSS will require must begin in teacher education, which includes coherence among program goals, science methods instruction, and field experiences (Lederman \& Lederman, 2013). However, our questionnaire found that the selection of mentor teachers does not attempt to align current science standards, science methods classes, and program goals in teacher education with the selection and articulated responsibilities of mentor teachers during the student teaching practicum. Given the time investment science teacher educators may be spending cultivating dispositions and pedagogical commitments related to reform-oriented teaching to align their courses with the NGSS, this is a frustrating finding. Work to prepare PSTs for NGSS alignment may be negated within their student practicum, as student teachers tend to replicate what they observe and experience in their student teaching practicum (Zembal-Saul et al., 2002). A possible future research study might expand the 
questionnaire across more states and allow for a comparison of mentor teacher recruitment efforts and practices among states that have and have not adopted the NGSS.

Finally, a synthesis of our results suggests that incentives to volunteer to be mentor teacher are minimal and include a small stipend, continuing education credit, or the ability to use college/university facilities such as the gym and pool. Despite this, field placement offices reported, and we concur, that mentor teachers are expected to play an important role inducting the PST into the teaching profession. Being a mentor teacher is a time-intensive endeavor. Adding professional development, as we suggest above, to support the mentoring teacher in learning how to mentor the PST increases his or her time burden. Therefore, we recommend that teacher education programs include incentives that align with the immense responsibility of local mentor teachers, such as course credit, money for classroom supplies, or access to college and university programs to build their content and pedagogy (such as summer science experiences).

Overall, our findings do not surprise us given how little support has been provided for selecting and defining mentor teachers at national and/or state levels (Clarke et al., 2014; Greenberg et al., 2011). Across disciplines, little is known about what qualities, dispositions, or practices make for successful mentoring relationships between in-service teachers and PSTs or whether those factors are hierarchical (i.e., Is pedagogical alignment more important than personal chemistry or vice versa?; Clarke et al., 2014). Yet the consensus within the field, both specifically within science education as well as within education more generally (Grossman et al., 2012; Rozelle \& Wilson, 2012; Zembal-Saul et al., 2002), is that the in-service teacherPST mentoring relationship is crucial to the success of student teaching practicums and mentoring is critical for persistence in the field. Therefore, it follows that science teacher preparation programs and science education researchers should invest significant efforts in identifying the components of successful mentoring and developing research-based professional development for educative mentoring for both PSTs and mentor teachers.

We recognize that although we have provided recommendations at the local level, this issue expands wider than college and university science teacher preparation programs and enters into the national debate about determining teacher quality and qualifications (i.e., teacher quality), as those are factors necessary for determining criteria to host a student teacher, which may be why selecting and defining mentor teachers has been left open for so long (Grossman et al., 2012). Yet as the literature also highlights, mentor teacher beliefs and practices should be aligned with teacher preparation programs, which is possible to do at the local level. This study underscores the need for further research around developing and supporting professional relationships between mentor teachers and PSTs, not just in science education but across teacher preparation.

\section{Disclosure statement}

No potential conflict of interest was reported by the authors.

\section{ORCID}

Mandy Biggers (1) http://orcid.org/0000-0003-2757-4592

Alison Riley Miller (1) http://orcid.org/0000-0002-7990-674X

Laura Zangori (D) http://orcid.org/0000-0002-7512-5559

Brooke A. Whitworth (D) http://orcid.org/0000-0002-3944-291X 


\section{References}

Bhattacharyya, S., Volk, T., \& Lumpe, A. (2009). The influence of an extensive inquiry-based field experience on pre-service elementary student teachers' science teaching beliefs. Journal of Science Teacher Education, 20(3), 199-218. doi:10.1007/s10972-009-9129-8

Blocker, L. S., \& Swetnam, L. A. (1995). The selection and evaluation of cooperating teachers: A status report. The Teacher Educator, 30(3), 19-30. doi:10.1080/08878739509555084

Clarke, A., Triggs, V., \& Nielsen, W. (2014). Mentor teacher participation in teacher education: A review of the literature. Review of Educational Research, 84(2), 163-202. doi:10.3102/0034654313499618

Comstock, G. (2013). Research ethics: A philosophical guide to the responsible conduct of research. New York, NY: Cambridge University Press.

Cross, F. (2017). Teacher shortage areas. Nationwide listing. 1990-1991 through 2017-2018. Washington, D.C.: U.S. Department of Education, Office of Postsecondary Education.

Dillman, D. A., Smyth, J. D., \& Christian, L. M. (2014). Internet, phone, mail, and mixed-mode surveys: The tailored design method. Hoboken, NJ: John Wiley \& Sons.

Feiman-Nemser, S., \& Buchman, M. (1985). Pitfalls of experience in teacher preparation. Teachers College Record, 87(1), 53-65.

Greenberg, J., Pomerance, L., \& Walsh, K. (2011, July). Student teaching in the United States. National Council on Teacher Quality, 1-44. Retrieved from www.nctq.org/edschoolreports/studentteaching

Grossman, P., Ronfeldt, M., \& Cohen, J. J. (2012). The power of setting: The role of field experience in learning to teach. In K. R. Harris, S. Graham, T. Urdan, A. G. Bus, S. Major, \& H. L. Swanson (Eds.), APA educational psychology handbook, Vol. 3. Application to learning and teaching (pp. 311-334). Washington, DC: American Psychological Association. doi:10.1037/13275-023

Haney, J. J., \& McArthur, J. (2002). Four case studies of prospective science teachers' beliefs concerning constructivist teaching practices. Science Education, 86(6), 783-802. doi:10.1002/(ISSN)1098-237X

Haynes, S. N., Richard, D., \& Kubany, E. S. (1995). Content validity in psychological assessment: A functional approach to concepts and methods. Psychological Assessment, 7, 238. doi:10.1037/ 1040-3590.7.3.238

Ingersoll, R. M., \& Perda, D. (2010). Is the supply of mathematics and science teachers sufficient? American Educational Research Journal, 47(3), 563-594. doi:10.3102/0002831210370711

Lederman, N., \& Lederman, J. (2013). Next generation science teacher educators. Journal of Science Teacher Education, 24(6), 929-932. doi:10.1007/s10972-013-9359-7

National Academies of Sciences, Engineering, and Medicine. (2018). Design, selection, and implementation of instructional materials for the next generation science standards: Proceedings of a workshop. Washington, DC: The National Academies Press. doi:10.17226/25001

National Research Council. (1996). National science education standards. Washington, DC: Author. Washington, DC: The National Academies Press.

National Science Teachers Association. (2017). NSTA position statement: Science teacher preparation. Retrieved from http://static.nsta.org/pdfs/PositionStatement_TeacherPrep.pdf

Newman, I., \& McNeil, K. A. (1998). Conducting survey research in the social sciences. Lanham, MD: University Press of America.

NGSS Lead States. (2013). The next generation science standards: For states, by states. Washington, D.C.: National Academies Press.

Patton, M. Q. (2002). Qualitative research and evaluation methods. Thousand Oaks, CA: Sage.

Rozelle, J. J., \& Wilson, S. (2012). Opening the black box of field experiences: How mentor teachers' beliefs and practices shape student teachers' beliefs and practices. Teacher and Teacher Education, 28(8), 1196-1205. doi:10.1016/j.tate.2012.07.008

Shamoo, A. E., \& Resnik, D. (2009). Responsible conduct of research (2nd ed.). New York, NY: Oxford University Press.

Smith, T. M., \& Ingersoll, R. M. (2004). What are the effects of induction and mentoring on beginning teacher turnover? American Educational Research Journal, 41(3), 681-714. doi:10.3102/00028312041003681

van Driel, J. H., Verloop, N., \& de Vos, W. (1998). Developing science teachers' pedagogical content knowledge. Journal of Research in Science Teaching, 35(6), 673-695. doi:10.1002/(ISSN)1098-2736 
Virginia Commonwealth University (VCU). (2002). Faculty mentoring guide. Retrieved June 6, 2015, from http://www.medschool.vcu.edu/media/medschool/documents/fmguide.pdf

Zembal-Saul, C., Krajick, J., \& Blumenfeld, P. (2002). Elementary student teachers' science content representations. Journal of Research in Science Teaching, 39(6), 443-463. doi:10.1002/tea.10032

\section{Appendix: PST Education Program Questionnaire}

1. Your name and program name

2. Who is responsible for science teaching practicum placements? (Please provide name, title, email, and phone number)

3. Will you have any preservice science teachers completing their practicum this spring (2017)?

How many student teachers in science were placed by your program in each of the last three academic years?

4. $2013-14$

5. $2014-15$

6. $2015-16$

7. How do you recruit mentor teachers for science teaching practicum placements?

8. What qualifications must a science teacher have in order to be selected as a mentor teacher for your program?

9. Does adherence of individual mentor teachers or whole schools to science standards, whether state or national (NGSS), play a role in where you place student teachers?

10. What are the expectations and responsibilities of mentor teachers who work with your program?

11. What incentives, if any, is a mentor teacher offered for mentoring a student teacher?

12. Are there other things that are important to note?

Note. NGSS $=$ Next Generation Science Standards. 